\title{
TRAMAS CONYUGALES... UNA MIRADA A LOS TEMAS DE CONFLICTO ENTRE LAS PAREJAS DE LA CIUDAD DE SANTIAGO DE CALI 2001
}

Rubén Darío Garzón M 


\title{
RESUMEN
}

\begin{abstract}
Las violencias conyugales en Cali, en el año 2001 se encuentran atravesadas por diferentes temas de discusión y conflicto entre las parejas que terminan en diferentes actos físicos y contenidos verbales que violenta, lastiman y destruyen la individualidad y las relaciones sociofamiliares. En los temas de conflicto encontramos un elemento común que los atraviesa como lo es la tensión existente frente a la imposición de la identidad de género tradicionales, bien sea desde el hombre celoso que quiere mantener a la mujer como objeto de propiedad afectivo y sexual, el desacuerdo relacionado con las actividades domésticas, el control que realiza el hombre sobre la vida sexual y afectiva de la mujer a través de los hijos, o bien desde el resquebrajamiento de las relaciones de poder en la familia.
\end{abstract}

\section{INTRODUCCIÓN}

1 presente artículo hace parte del trabajo investigativo: Trama Conyugal...La Primavera Gris, él da cuenta del ejercicio investigativo desde la perspectiva cualitativa, en el cual se analizan un total de 39 entrevistas semiestructuradas realizadas a mujeres entre los trece (13) y veinte (20) años denunciantes de violencia intrafamiliar en la ciudad de Cali en el primer periodo del año 2001 y remitidas por diferentes autoridades locales al Instituto Nacional de Medicina Legal Y Ciencias Forenses para el estudio el caso a propósito del delito de Violencia intrafamiliar.

En este artículo se hace un recorrido general por los temas de conflicto entre las parejas, se abordan, en su orden, el complejo tema de los celos, la crianza de los hijos, las actividades domesticas, las relaciones de poder, las relaciones con la familia extensa, y el consumo de sustancias psicoactivas como temas que tensionan las vidas de hombres y mujeres en la ciudad de Cali.

El conocer los temas de conflicto entre las pareja reviste de importancia dado que - en el marco de la escena vital - junto a los factores de riesgo, nos constituyen el contexto de producción del delito, para el análisis criminológico de la conducta, dándonos elementos para prevenir y comprender los hechos de violencia que entre cónyuges se generan y mantienen. 


\section{A PROPÓSito de los TEMAS DE CONFLICTO EN LAS RELACIONES CONYUGALES...}

\subsection{Tema de tensión de las relaciones: CELOS}

Uno de los temas que tensionan las vidas de las parejas se remite a los celos, estos entendidos desde la perspectiva individual donde la persona afectada está respondiendo a lo que percibe como una amenaza que un tercero representa para una relación que ella considera como valiosa. Esto último, es valido aún en el caso que el tercero sólo exista en la imaginación de la persona celosa. Los celos están conectados con el temor arraigado en la idea de perder algo que se tiene o se cree tener.

Frente al tema de los celos, diversos autores plantean que éstos pueden ser tanto necesarios como malignos para las relaciones. Los limites podrían estar en el tipo e intensidad de las reacciones que se tengan al experimentarlos, así como en la naturaleza de la amenaza experimentada frente a la relación amorosa.

\section{Celos normales $^{1}$}

Los celos se pueden considerar como un sentimiento normal cuando experimentamos miedo de perder el afecto de una persona basándonos en hechos reales, que nos indican que existe el riesgo que esta persona elija a otra como objeto del afecto que hasta ahora nos había dispensado a nosotros. Este hecho se da principalmente en la pareja cuando aparece una tercera persona que desplaza a uno de los componentes pudiendo llegar a sustituirle.

\section{Celos patológicos}

En contraste con los celos "normales", en los relatos hechos por las mujeres denunciantes de violencia intrafamiliar, se encuentra que existe un lado oscuro en estas pasiones: celos patológicos que pueden llevar a trágicas consecuencias, tanto en quien los padece, como en el objeto de los celos.

Una persona patológicamente celosa cree que es dueña de los sentimientos de su pareja, rompiendo el equilibrio que supone la unión de dos personas con iguales derechos. Ahí comienzan los celos que, paulatinamente, van socavando la personalidad y bienestar de ambos.

En los celos patológicos se encuentra la suposición errónea de que uno tiene un reclamo o derecho sobre la vida de su compañero o compañera, especialmente sobre la vida sexual de esa persona.

${ }^{1}$ Reconociendo la complejidad del asunto, pero con la necesidad de diferenciar las reacciones asociadas a los celos, de manera artificial se hace la nominación: Normales - Patológicos. 
En los celos patológicos se presenta una reacción destructiva mediada por pensamientos malos e injustos sobre el compañero o la compañera. Una amargura de origen irreal, cinismo o malevolencia hacia la víctima. Esas emociones negativas generalmente continúan aumentando hasta que finalmente sobrepasan todos los buenos sentimientos y valores entre las personas. En ese momento el amor y la relación son destruidos.

El compañero o compañera con celos se encierra en la idea que cualquier relación o aventura externa representa una amenaza o privación. Además, la persona con celos patológicos erróneamente juzga a su compañero o compañera en términos de experiencias de pareja no paralelas, en vez de juzgar en términos de su relación actual. (Concepto 63, Enciclopedia de Referencia Neo-Tech.)

En resumen cabe decir que la mayoría de las personas experimentan celos "normales" cuando una amenaza real se cierne sobre una relación que valoran; esta emoción puede estar atravesada por variadas ideas que pueden ir o no en perjuicio de la imagen que se ha construido de la pareja (hombre o mujer), tras éstas emociones y pensamientos se presentan diferentes tipos de reacciones y con ellas posibilidades de daño a la persona objeto de los celos, tornándose en celos patológicos al estar atravesado este proceso por una amenaza irreal.

Los celos son normales o patológicos dependiendo de la naturaleza de la amenaza, el tipo y grado de la reacción ante este sentimiento.

Se encuentra que asociado a los celos normales aparece una reacción ante una amenaza real, reacción que puede estar o no relacionada con la violencia; así mismo tenemos que los celos patológicos están asociados a una amenaza irreal donde la reacción del individuo celoso igualmente podría estar asociada a la manifestación de violencia. La violencia en el proceso de los celos se puede presentar tanto en celos normales como patológicos.

\section{De lo individual y lo cultural asociado a los celos}

El tema de los celos se encuentra atravesando lo individual dado que como personas experimentamos y reaccionamos mediados por diferentes emociones y pensamientos; y lo cultural en la medida que como hombres y mujeres nos construimos en culturas y contextos históricos determinados e influyentes en la forma como nos relacionamos con el mundo, con nosotros, con los otros y con la otras.

\section{De las experiencias intrapsíquicas asociadas a los celos}

Teniendo como base los relatos y conceptos con relación a los celos, se encuentra que son variadas las experiencias intra psíquicas experimentadas por los individuos hombres y mujeres en el contexto de los celos. Según la trabajadora social Luz Mery Sánchez, estas experiencias "unas veces se inclinan más al temor, el dolor, la vergüenza, la tristeza, la tendencia al apartamiento y en otras ocasiones se inclinan más a las 
sensaciones de cólera, disgusto, irritabilidad, hostilidad”. (Sánchez, Luz Mery, 1990 en Maldonado Maria Cristina 1995 Pág.31-33).

Una persona que está celosa puede sentirse triste y malhumorada, porque tiene miedo a ser desplazado a un segundo plano, se mortifica pensando miles de motivos por las que lo van a dejar, así como miles de maneras como ese abandono se hará realidad; ese miedo le está diciendo que es posible que no lo quieran.

"El entró a la casa a insultarme porque el día anterior yo estaba conversando con un amigo; por celos, y ahí fue cuando me golpeo" (E:3)

En el relato se aprecia que la respuesta presentada por parte del hombre regularmente se asocia a la experiencia de disgusto, irritabilidad y hostilidad, atentando y vulnerando con ello, los derechos de la cónyuge y la estabilidad del vínculo emocional. Así mismo se evidencia cómo la emoción de malestar representada en el disgusto puede perdurar hasta el momento que se "libera" la energía emocional del malestar, en este caso por medio del insulto y el golpe.

En el ambiente familiar atravesado por los celos, se encuentra que las visitas de la ofendida a su familia de origen están cargadas de desconfianza por parte del esposo al dudar del destino final de la cónyuge (situación que se traduce finalmente en las dificultades en relación a la confianza básica del mismo individuo celoso), igualmente se encuentra desconfianza hacia las amistades de la esposa incluso femeninas, al pensar que éstas son medios por los cuales se hace real la presencia afectiva de otro masculino en la vida de la mujer.

"Las Discusiones son porque le dan celos, a veces piensa que no voy para mi casa sino para otra parte, que me voy a ver con el mozo; que como entro a la casa de una amiga, que ella es la que me hace el cuarto para verme con él” (moso). (E:25)

En el ámbito sentimental, se encuentra que el rasgo más acusado de los celos es la desconfianza y sospecha permanente en el otro que tiñen, y perjudican gravemente la relación con la persona amada. Las personas muy celosas frecuentemente, apasionadas, ansiosas; buscan con avidez todas las pruebas de su presunto infortunio y se muestran refractarios a los argumentos racionales que les trasmiten las personas cercanas con las que se sinceran.

"Él empezó a alegar, a insultarme, lo que pasa es que él es muy celoso y quiere celarme con el patrón de la casa donde cuidamos, y con un muchacho que era amigo mío, me decía que dónde había estado” . (E: 26)

Cuando se siente celos, pueden aparecer referentes o personas "fijas" frente a las cuales se experimentan, o bien pueden aparecer una serie indiferenciada de personas, en este caso masculino: Empleador o jefe, personas conocidas o amigos de la ofendida... Cualquier otra persona (hombre o mujer) es un (a) rival potencial que asume como real la persona celosa. 
El celoso desconfía entonces de las visitas a familiares y amig@s de la esposa o mujer, exige a su pareja la descripción pormenorizada de su supuesta aventura y en su mente se mezclan el miedo al ridículo, a estar en boca de todos, el sentir con dolor que la otra persona vale más, la auto-descalificación, un deseo morboso de información:

Por ejemplo, le preguntará enfadado: ¿đónde has estado?, ¿Con quién has estado?, ¿Qué has hecho? ¿de que has hablado? ¿cómo te miraba? ¿qué ropa tenías?... Su pareja puede decirle la verdad, que ha estado en casa de sus padres, comiendo o simplemente hablando, pero él no la cree, porque está celoso: “¿No será que está con otro? “¿No será que ya no me quiere?" Y al pensar que su pareja miente, en lugar de calmarse, aumenta su malestar. ¡Y cuando creyese la versión de ella, por las razones que fueran (porque llamó a su suegra para preguntarle si era verdad, o porque al final se cansó de oír de su pareja siempre la misma explicación), seguirá triste y malhumorado porque pensará que su pareja lo va a dejar por su familia! ¡Quiere más a su familia que a mí! ¡Quiere más a sus amigas que a mí! ¡Quiere más al perro que a mí! ... Siempre miedo a que su pareja quiera más a otro ser.

Ella, para no molestarlo más -porque lo quiere-, dejará de visitar a su familia o lo hará a escondidas para que él no se entere. Y con el tiempo dejará de visitar a sus amigos, familiares, vecinos, generándose con ello aislamiento social o resquebrajamiento de las redes socio familiares de apoyo, llegando a constituirse la relación conyugal en su único mundo posible. Lo cierto es que cualquier cosa que su pareja haga o deshaga sin ser él el centro de atención, le pondrá triste y malhumorado.

En los celos patológicos, la persona celosa rápidamente puede pasar del pedir detalle pormenorizado de las acciones de la pareja a acusar, espiar o seguir insistentemente a su pareja, con el fin de demostrar la infidelidad, llegando a registrar su ropa o incluso oler a la mujer en busca de evidencia que justifiquen sus acciones, o bien puede llegar a asignarle un significado a la acción de terceros, proceso de significación siempre atravesado por la desconfianza y el temor a la pérdida, a no ser suficientemente digno de amor... La agresión física se constituye, en estos casos, en un hecho inminente.

"Si iba a salir, tenía que pelear con él y me golpeaba; después iba a la casa de mi mamá y me iba hacer escándalo: "que me tenía que ir para la casa" quería que a toda hora viviera encerrada” (E:1)

"La separación fue porque era muy celoso y me golpiaba, me insultaba. Discutimos porque él dice que yo tengo otro y yo no tengo a nadie, porque no quiero volver con él, por eso me agredió” . (E: 29)

\section{De los textos en el contexto cultural}

En los relatos presentados si bien se aprecia que las experiencias intra- psíquicas que se viven cuando se experimentan celos pasan por el disgusto, la irritabilidad y la hostilidad reflejadas de manera directa en la acusación, el insulto y el golpe; observamos también 
que quienes los experimentan son hombres y mujeres construidos en una cultura y tiempo determinados donde se desenvuelven sus vidas. Los celos varían de una cultura a otra, en el contexto de construcción por genero, la cultura influye en la manera en que se viven, y se expresan.

De esta manera se encuentra que la forma como se viven y manifiestan los celos depende tanto de los recursos individuales con los que cuente cada uno de los miembros de la pareja (autoconcepción, seguridad, elaboración de perdidas afectivas anteriores, necesidades emocionales satisfechas, autodeterminación, percepción del otr@, etc.), como por la condición sociocultural de género; contexto en el cual hay que señalar las diferencias que se pueden experimentar al estar estos individuos, hombre y mujer en un contexto que influye en la manera como se interpreta el mundo de los hechos y símbolos, mundo que influye en cómo sienten y cómo se expresan los celos.

"La discusiones son por celos de él, yo también lo celo, hasta octubre, de ahí para

allá no, él me dice que si tenía otro?”. (E: 27)

"Hace como cinco meses, dijimos que íbamos a cambiar porque yo también lo celaba, yo cumplí con no volverlo a celar pero él no”. (E:1).

En los relatos se muestran los pesos socio-culturales y personales desde lo masculino y lo femenino al experimentar y expresar los celos. Se llega a acuerdos frente a la reacción celosa, lográndose - aunque de manera parcial - en la mujer. Situación que lleva a preguntarnos: ¿Qué diferencias existen entre hombres y mujeres al intentar transformar sus reacciones celosas?... Se aprecia que desde el masculino se continuó con la experimentación y manifestación de los celos, interpretando el no deseo en la mujer de continuar con la relación conyugal, a la presencia de otro masculino... la sombra eterna... Es decir, ante la negativa de continuar la relación conyugal en la mujer, elección libre y autónoma, en muchos casos, desde el compañero o esposo se considera que dicha decisión está mediada por la presencia afectiva y/o sexual de otra persona en la vida de la mujer... No se acepta que por la historicidad de la relación, la mujer llegue a la decisión de terminar sin que sea necesario la presencia de otra persona.

Desde una perspectiva cultural "Cuando hablamos de celos se requiere mencionar la creencia del derecho a la posesión de la persona que se constituye en objeto de los celos". (G. Simmel 1997 en Maldonado, María Cristina 1995, pág.31) En las entrevistas, se encuentra que el "encierro" en esta relación de posesión aparece como un indicio (efectivo o en el discurso) con el cual se sugiere que al experimentar los celos se quiere mantener el control de aquello que considera le "pertenece".

"Él me cela, que no puedo salir a ninguna parte". (E:30)

"El me cela, discutimos por eso, él no me deja tener amigos ni amigas". (E:31) 
El encierro en este contexto cobra importancia en el sentido que es por medio ${ }^{2}$ del cual el individuo celoso se "asegura" que su "objeto" carezca de otros referentes con los cuales recrear la vida, sentirse mejor, encontrar la felicidad o simplemente carezca de otras personas que hagan parte de su mundo afectivo, intentando conjurar así, la amenaza, muchas veces irreal.

Una mirada a los relatos permite apreciar que en nuestra sociedad, el encierro (efectivo o en el discurso) se hace mucho más evidente o posible desde el masculino sobre lo femenino - rara vez se escucha que la mujer le prohíba salir al hombre -. Este ejercicio del encierro lleva a pensar el ámbito privado para lo femenino y el ámbito público para lo masculino, pues históricamente se encuentra que el espacio doméstico fue destinado para las mujeres, las cuales eran de y para la casa, lográndose con ello la organización con predominancia masculina en la toma de decisiones en tanto manejan y suministran los recursos y propiedades, quedando subordinad@s a esas decisiones la mujer e hijos dependientes. En el contexto de la instrumentalidad de la violencia ${ }^{3}$, se encuentra el encierro como un medio a través del cual (se ejerce violencia física cuando es efectivo a través del uso del espacio) se asegura aquel con comportamientos celosos que el objeto de los celos se aislé de toda persona que pueda ocupar el mundo afectivo y sexual... su territorio.

Pero, ¿Cuál es la relación que podría existir entre el encierro y la condición masculina, además de instrumentalmente serle útil para sus fines (controlar) racionalmente mentados (Sentido de las acciones - Weber Max)? En Bourdieu, encontramos que la relación podría estar en la división de las cosas y de las actividades (sean o no sexuadas) en el contexto de la oposición masculino - Femenino, contexto en el cual aparece la cultura dando un orden al mundo social.

El orden social funciona como una inmensa máquina simbólica que tiende a ratificar la dominación masculina en la que se apoya: es la división sexual del trabajo, distribución muy estricta de las actividades asignadas a cada uno de los dos sexos, de su espacio, su momento, sus instrumentos, la estructura del espacio, con la oposición del lugar de reunión o de mercado reservado para los hombres y a la casa reservada a las mujeres, o, en el interior de esta. El programa social de percepción se aplica a todas las cosas del mundo (Bourdieu Pierre 2000.Pág 22), y los hombres de los relatos como personas inscritas en el mundo de las cosas, de los hechos y de las percepciones reflejan en sus acciones concretas cómo la percepción construida social, histórica y culturalmente en relación

\footnotetext{
${ }^{2}$ Nótese que uno de los medios por el cual se puede ejercer violencia física frente al cónyuge es el espacio, bien sea mediante la ejecución directa del encierro, o por medio de amenaza que obliga a la persona objeto de los celos quedar restringida a dicho espacio.

${ }^{3}$ Desde la idea de Arentd Hanna en cuanto a que la violencia es un medio para lograr determinados fines, apareciendo a con las acciones de violencia múltiples formas e instrumentos. Ver Arendt Hanna. Sobre la Violencia 1970.
} 
con el otro sexo los atraviesa manteniéndoles y reafirmándose en el mundo masculino, pero deteriorando sus relaciones de pareja y de vida en el amor.

"Las discusiones son porque él es un posesivo, un idiota, es un celoso.. Él me

quiere tener en una cajita de cristal" (E:34)

Pero si bien existe todo un acumulado histórico que referencia el espacio doméstico y de dependencia (en tanto obediente y fiel) al género femenino, hoy la humanidad cuenta con grandes experiencias de transformación donde las mujeres han participado de manera activa ${ }^{4}$. Es así como en un gran sector de la población femenina se desarrollan procesos individuales y colectivos, procesos de transformación acerca de su rol en la pareja y en la familia, esta transformación se encuentra mediada por el cuestionamiento preceptos tradicionales (casa, e hijos); procesos de transformación que evidencia el resquebrajamiento de las relaciones de poder en las parejas mediado a su vez por el resquebrajamiento de las identidades de género ${ }^{5}$ (específicamente frente a lo femenino) culturalmente construidas. Es decir existe un cuestionamiento a la relación dominante / dominado, cuestionamiento sobre cómo se debe dar el desarrollo de la familia, los roles a asumir por el hombre y la mujer, se cuestiona en el ámbito individual o colectivo la dictadura atávica de lo masculino.

En el proceso general de los celos, mediado por el resquebrajamiento de las relaciones de poder, se encuentra que cuanto más persigue a su pareja con celos, tanto más se siente impulsada (en este caso) la perseguida a demostrar su autonomía, esforzándose en alejarse y no dejarse obligar. Y cuanto más lo hace, tanto más busca el celoso o celosa reclamarle como posesión propia y secuestrar su libertad de movimientos y de sentimientos...Se muestra entonces que el encierro - efectivo o al cual se hace referencia - es uno de los medios utilizados por hombres que experimentan celos, queriendo con ello mantener el control y posesión de la mujer, eliminado las posibilidades de interacción social de vital importancia en el proceso de construcción social de los individuos.

\subsection{TEMA DE TENSIÓN DE LAS RELACIONES: CRIANZA DE LOS HIJOS}

Frente a este tema, se encuentra que las tensiones en la pareja se encuentran asociadas básicamente a la dimensión económica en tanto el aporte para la manutención y

\footnotetext{
${ }^{4}$ Por ejemplo las reivindicaciones de Derechos Civiles, Sociales y Políticos, las conquistas en el área penal relacionadas con la defensa de sus derechos en ámbitos domésticos (Colombia Ley 294 de 1996. Ley 599 de 2000 entre otras).

${ }^{5}$ La construcción de las identidades comprende dos procesos complementarios: El reconocimiento que cada persona hace de sí misma, como ser distinto y particular respecto a los demás. Y la apropiación del contexto cultural donde se desenvuelve, y la identificación con este como si fuera propio, sintiéndose como parte de la cultura y reproduciéndola como tal. (Puyana Yolanda. Bernal Margarita. 2000 Pág.19)
} 
satisfacción de las necesidades de subsistencia de 1@s menores.

La dimensión económica tiene que ver con los aportes a los hijos, en términos de la alimentación, educación, recreación; necesidades frente a las cuales se muestra la ausencia del aporte. En términos generales el aporte económico para 1@s menores, está condicionado por el hombre a la vigencia de la relación conyugal, no separando las interacciones o determinaciones conyugales respecto a hacer vida junto a otra persona y las responsabilidades que se adquieren frente a un menor de edad al reconocerlos, siendo éstos los afectados por los problemas o dificultades en el mantenimiento de la relación marital.

"Discutíamos por la comida de los niños, como él no nos da nada, la mama de él es la que nos da la comida. A él no le gusta que yo salga, que esté ahí encerrada en la pieza de los niños. Discutimos porque yo no quiero vivir con él. (E:31)

"Porque le pido la comida de las niñas, y porque yo le digo que no quiero tener nada con él y él me dice que tengo que seguir que por las niñas, que nos vamos a vivir" (E:35)

"La comida de los niños, él dice que no me va a pasar nada porque yo no vivo con él”. (E:29)

"Yo le decía que no quería volver a vivir con él, él decía que no, que tenía que vivir con él, que sino lo hacia se llevaba la niña para Venezuela.” ( E: 4)

En las discusiones que involucran el tema de los menores, igualmente se evidencia las relaciones de conflictividad con la familia extensa de uno de los cónyuges, generándose fricciones en la pareja por las visitas que se realizan a la familia de origen.

"Las discusiones son por bobadas, por el mal genio de él, a veces por el bebé, él no

se quiere con mi familia y a él no le gusta que yo lleve el niño a mi casa, a él le da

rabia que cuando llega, yo estoy en mi casa”. ( E: 13).

En las familias que atraviesan por la etapa denominada Familia con Niños Preescolares, se aprecia un momento vital dentro del proceso de desarrollo familiar, en la medida que tanto a nivel de pareja como individual, los ajustes a las nuevas exigencias parentales, pueden no coincidir con las motivaciones personales. O bien por las relaciones de hostilidad con las familias extensas desde los miembros de la familia de procreación. Este periodo familiar supone manejar características específicas del infante, donde todavía es muy heterónomo, egocéntrico y por lo tanto dependiente de las figuras parentales para satisfacer todas sus demandas afectivas y físicas. Como características más recurrentes, en este periodo, se presenta el desplazamiento de los conflictos maritales a la crianza y cuidado de los niños, constituyéndose los menores en una especie de "chivos" expiatorios de los problemas maritales; así como nuevos problemas económicos por las exigencias de los hijos. 
En los relatos tenemos que los conflictos del mundo conyugal son desplazados a las funciones parentales como una medida de presión para el mantenimiento del vínculo emocional, sexual, y social de la conyugalidad, vulnerándose con ello el sustrato de toda interacción humana por principio como lo es la autodeterminación. Para el caso concreto, se instrumentaliza a los menores, e incluso se condicionan los recursos que afectan su crecimiento y desarrollo... en el contexto de la crianza de los hijos en el marco general de la violencia conyugal, desde una perspectiva ético, podríamos decir que los menores aparecen como instrumentos y no como fines en sí y para sí, viéndose atentado y vulnerado con ello su condición humana.

\subsection{TEMA DE TENSIÓN DE LAS RELACIONES: ACTIVIDADES DOMESTICAS:}

Dentro de las particularidades del tema relacionado con las actividades domésticas, encontramos que este tema puede estar atravesado tanto por la lógica del desplazamiento de la tensión socio-laboral al espacio familiar; como por la incongruencia de expectativas frente al rol tradicional a desempeñar por la mujer (Garzón, Rubén D. 2.000 Pág. 50). Las expectativas en cuanto al prototipo cultural del hombre o mujer se encuentran en desacuerdo con las acciones que realiza una o ambas personas en la relación conyugal.

A propósito, María Cristina Maldonado nos refiere lo siguiente: "Principalmente se actúa violentamente cuando se dan desacuerdos en la familia sobre el incumplimiento de las expectativas y "deber ser" del comportamiento femenino o masculino, la conducta que se espera de los jóvenes y de los adultos, de las funciones del padre, de la madre. (Maldonado, María Cristina 1999. Pág.8 ).

Una particularidad frente al tema de las actividades domésticas suele ser que el ejercicio de la violencia en la casa, está relacionado con el desplazamiento del conflicto de lo público a lo privado, es decir, cuando el hombre presenta discusiones o conflictos con otras personas como compañeros de trabajo, jefes, o amigos; en este desplazamiento del conflicto de lo publico a lo privado, se aprecia que lo femenino doméstico en el contexto de las relaciones de poder, representa un figura no amenazante para el masculino, apareciendo asuntos relacionados con el quehacer tradicional femenino: cuidado de hijos y mantenimiento del hogar, como desencadenante de las agresiones.

De otro lado, la insatisfacción frente al desempeño domestico de las mujeres, es un elemento que entra a dar cuanta del no acuerdo entre las expectativas de los cónyuges y la realidad - que encuentran o la que se construyen para sí -pues el dominante tradicional masculino continua esperando lo que se ha construido en cuanto al rol femenino y reproducido por éste en el marco de la violencia simbólica, en términos que la mujer asimile como propios y naturalice quehaceres, o estilos de vida, modos de pensar y reaccionar, impuestas desde el mundo dominante. Se encuentra entonces que tras la 
queja del hombre respecto al no cumplimiento del rol femenino, se haya el afán de mantener el statu quo, en términos de la reproducción de roles e identificaciones con actividades y espacios: Domesticas- espacio privado.

Pero en el campo de las acciones y retroacciones, asociadas a la dinámica particular de cada familia, encontramos que este no cumplimiento con el rol femenino podría leerse desde el punto de vista de revelarse, o resistirse de manera indirecta a continuar con dicho rol, o como una medida de protestar ante el contexto de violencia en que se vive, es una manera indirecta de cuestionar la imposición de voluntades en otros campos, se podría pensar que en la respuesta de la mujeres se refleja tal vez una de las formas como se cuestionar la relación de poder y violencia general: el no cumplir -desde la estrategia o desde el inconsciente- con su rol.

"Cuando discutíamos, cuando él me gritaba, era cuando llegaba de la calle malgeniado, le salía algo mal y venia se desquitaba conmigo. Cuando discutíamos era porque él me gritaba cuando se me olvidaba lavar algo de bebé, él me mantenía diciendo lo que tenía que hacer, sabiendo que yo lo hacia, sólo que a veces se me olvidaba algo”. (E: 1)

"Yo le hacía su almuerzo y él decía que yo no sabía cocinar, que estaban las cosas sucias, yo siempre lo he hecho y él nunca se había quejado de nada”. (E: 30)

\subsection{TEMA DE TENSIÓN DE LAS RELACIONES: RESQUEBRAJAMIENTO DE LA RELACION DE PODER.}

Máx Weber (1.969) define el poder como "una imposición de voluntad de un individuo o grupo sobre otro u otros. Implica interacciones de influencia mutua en dos direcciones desde el dominio y la subordinación. El dominante requiere quien le asegure que puede dominar y en consecuencia el otro se lo garantiza, influyendo sobre el dominante, afirmando su capacidad y otorgándole la posibilidad de dominar; el dominado únicamente pierde su libertad y espontaneidad en el caso de violencia física y en forma extrema con la muerte.

H. Arendt (1970), respecto a las relaciones de poder y su relación con la violencia plantea que "cuando el poder se resquebraja, debilita o se pierde las fluctuaciones de la vida social y familiar, surge violencia. Los actos violentos se realizan desde el dominante y el dominado haciendo uso de aquellos medios para ejercer poder y para imponer la voluntad por la fuerza.

"Los recursos", plantea Maldonado definen en gran parte las relaciones de dominio y subordinación. La determinación de quién manda y quién obedece, en parte, se da por los recursos que se poseen y los derechos que se cree tener para manipularlos. Poseer tierra, trabajo, vivienda, utensilios domésticos, herramientas de trabajo, conocimientos, habilidades, otorga la capacidad de mando, posibilidad 
de unos de imponer su voluntad a otros para su propio beneficio, el de los otros o mutuo” (Maldonado, María Cristina, 1995 pág. 39,55-)

Las relaciones de poder son consustanciales al conjunto social, es decir las relaciones sociales de una u otra manera se encuentran inmersas en contextos donde circula y se ejerce poder. Cuando no hay acuerdo sobre la manera como se ejerce este poder, sobre el contenido de las imposiciones, la violencia surge como un medio para imponer voluntades o mantener el control de la relación, a la vez que reproduce el dominante tradicional.

En los relatos se encuentra cómo un acto de ejercicio de las libertades individuales en el caso de la mujer, es asumido e interpretado como un acto de "desobediencia" y afrenta ante la condición masculina, apareciendo la acción violenta como una castigo a la "falta".

"Él sábado por la noche, por la casa de él, vive una amiga de mi hermana, nosotras le íbamos a llevar un cuaderno, el me había dicho que yo no podía andar por allá, por donde él vive, yo le dije que yo era libre de caminar por donde yo quería, me dijo que ya me había dicho que no podía andar por allá, cogió y me patió” (E: 27)

El resquebrajamiento de las relaciones de poder, puede darse a partir de una acción puntual de "ejercicio de la libertad" o desde la "desobediencia", es decir a partir de lo analógico, las acciones cargadas de significado; también puede darse a partir del lenguaje verbal en sí. El resquebrajamiento de la relación de poder se puede presentar a partir de la manifestación verbal del no acuerdo sobre las características de dicha relación.

“...También discutíamos y porque él me gritaba y a mi no me gustaba, yo le contestaba y ahí empezaban los problemas” (E: 13)

"Las discusiones son por nada, a él no le gusta que uno le hable duro porque ya dice que uno lo esta gritando, me dice que vaya a gritar a mi mamá que el no es hijo mío para que yo lo esté gritando, o a veces el llama desde lejos y uno no oye y uno no le contesta y a él le da rabia y se viene como si uno fuera hijo de él a pegarle. (E:26).

En los relatos encontramos que si bien, desde muchos hombres se sigue ejerciendo el rol tradicional dominante, así mismo desde muchas mujeres en relaciones de pareja, se encuentra que empiezan a cuestionar dichas relaciones, resquebrajando desde su ejercicio analógico o verbal las identidades de subordinación. Podríamos pensar que un aspecto que contribuye al resquebrajamiento de las identidades tradicionales de subordinación y ejercicio del poder se encuentra que asociado a las tareas y los espacios de vida cotidiana en hombres y mujeres, en la medida que en la actualidad dada las condiciones socioeconómicas de las familias colombianas, así como cada vez es más difícil el acceso a los recursos para la satisfacción de las necesidades, y logros laborales y educacionales en las mujeres, encontramos que la división sexual del trabajo se encuentra en transición, transformación y por ende la distribución del poder y su ejercicio. 


\section{Relación con la familia extensa...}

Las relaciones con la familia de origen de uno de los cónyuges en un núcleo de conflicto entre las parejas, bien sea porque existen niveles de hostilidad declaradas entre el cónyuge y los familiares de las ofendidas, o bien porque desde miembros de la familia de origen se presentan ingerencia en la vida familiar apareciendo temas como el dinero, la procreación y las visitas familiares.

"Que porqué no me quedaba en la casa de él. Porque mi mamá se mete en la relación de nosotros, lo que pasa es que mi mamá no quería que él me metiera más hijos porque eso es lo que él quiere hacer conmigo". (E. 36)

"Las discusiones son por que él no se quiere con mi familia y a él no le gusta que yo lleve el niño a mi casa, a él le da rabia que cuando llega y yo estoy en mi casa". (E:25)

\section{La droga que envenena...}

El consumo de sustancias psicoactivas como el alcohol y otras sustancias socialmente no tan aceptadas se encuentran atravesando las relaciones de conflicto entre las parejas, bien sea por las frecuentes manifestaciones de celos en los individuos consumidores de alcohol, las manifestaciones de violencia directa o indirecta (contra propiedades) de las personas bajo efectos de las sustancias, o bien por ser desencadenantes de otros estresores familiares como lo es la falta de dinero para la satisfacción de necesidades dado los gastos que suponen las adicciones.

"Las discusiones eran por el vicio mas que todo". (E:33)

"Nosotros convivimos seis años, hace 10 meses estamos separados porque el tomaba mucho y no aportaba en la casa nada... el toma mucho, llega cansón a la casa, a gritar, a azotar cosas". (E: 36)

Antonio Seva, también nos hace aportes sobre la incidencia del continuado consumo de alcohol y/o drogas en la generación de actos violentos: “...En el uso y abuso de sustancias embriagantes y/o alucinógenas, pueden presentarse situaciones conflictivas con desenlaces violentos bien sea como consecuencia de la ingesta o por las circunstancias que rodean la obtención de las mismas.

Estas situaciones de violencia son debidas en unos casos al estallido de borracheras patológicas (en sujetos no necesariamente alcohólicos) en los que aparecen todo tipo de manifestaciones de desconfianza, perplejidad y delirio junto a una pérdida de controles que facilitan la agresión inesperada a veces consumiendo muy poca cantidad de alcohol. Otras veces, ya se trata de un alcohólico crónico que desarrolla además de sus embriagueces cargadas de agresividad, síndromes psicopatológicos en los que los celos y las ideas de perjuicio personal son causa de múltiples actos violentos". (Seva, Antonio. 1994. Pág. 176) 


\section{A MANERA GENERAL....}

Como vemos hoy las relaciones conyugales en la ciudad de Cali, están siento atravesadas por diferentes temas y discusiones que tensionan sus relaciones, temas que dado el manejo inadecuado a las mismas terminan transformándose en hechos de violencia que van desde las psicológicas, pasando por las físicas, económicas, sexuales, todas ellas con diferente grado de contundencia y desarrollo. Constituyendo así, bien sea el delito de violencia intrafamiliar u otros como la mismas lesiones personales o el homicidio, esto dependiendo del grado de lesión generada.

En los temas de conflicto encontramos un elemento común que los atraviesa como lo es la tensión existente frente a la imposición de la identidad de género tradicionales, bien sea desde el hombre celoso que quieren mantener a la mujer como objeto de propiedad afectivo y sexual, el desacuerdo relacionado con las actividades domésticas, el control que realiza el hombre sobre la vida sexual y afectiva de la mujer a través de los hijos, o bien desde el resquebrajamiento de las relaciones de poder en la familia. Temas de conflicto que nos dan cuenta que hoy - pese a sus grandes dificultades - las relaciones sobre las que se construye el ser esposo o esposa se están transformando y en esa transformación surge la tensión y la discusión....discusiones que al ser manejadas desde la perspectiva tradicional dominante masculina, regularmente terminan, como ya se dijo antes, en alguna de las manifestaciones de la violencia.

En este marco, y si como sociedad abordamos el contexto de producción del delito de la violencia intrafamiliar - conyugal (Garzón M. Rubén 2.000), determinando cuáles son lo focos de tensión y discusión que entre las parejas existe, así como los factores de riesgo que a diverso nivel están generando la violencia, podemos avanzar en el acompañamiento preventivo y terapéutico a las parejas que hoy en día se les va la primavera entre los dedos al experimentar en su cotidianidad violencias que marchitan la autonomía, el afecto, los sueños y la vida.

\section{BIBLIOGRAFÍA}

Bourdieu Pierre. La Dominación Masculina. Traducción Joaquín Jordá. Editorial Anagrama. Barcelona. 2.000

CONGRESO DE LA RepublicA DE COLOMBiA. Ley 294 de 1996, para Prevenir, Remediar y Sancionar la Violencia Intrafamiliar.

GARZÓN M. RUBÉN DARÍO. "El trabajo social en el campo de la acción forense". (artículo) Revista Prospectiva. Escuela de trabajo social y desarollo bumano. \# 4/5. Facultad de Humanidades. Universidad del Valle. Cali. 2000

El peritaje sociofamiliar Frente a la Violencia Conyugal. Universidad Libre Seccional Cali. Cali. 2000

LEY 599 Y Ley 600 Julio 24 DE 2000. Por la cual se expide el nuevo Código Penal Colombiano, y Nuevo

Código de Procedimiento Penal Colombiano. Congreso de la República de Colombia. 
Lorente, acosta. miguel. Estado del Arte en modelos de Atención de la Violencia Sexual. Bogotá. Sept. 29- 2001.

MALDONADO, MARÍA CRISTINA. Conflicto, poder y violencia en la familia. Universidad del Valle. Facultad de Humanidades. Escuela de Trabajo Social y Desarrollo Humano. Cali 1995

Conflictos y violencias: Justificaciones en la familia. Ponencia presentada en el primer congreso Internacional Violencia Social y Violencia Familiar: Una cuestión de Derechos Humanos. Universidad de Caldas, Manizales, Mayo 1999. - Memorias.

PUYANA YOLANDA. BERNAL MARGARITA. Reflexiones sobre violencia de pareja y relaciones de género. Modulo 4 Violencia intrafamiliar. Haz PAZ. Política nacional. Haz Paz. Presidencia de la República de Colombia. Bogotá. Diciembre 2000

Seva, Antonio. Bases Psicopatologicas de la Violencia Familiar, Laboral y Comunitaria. Ponencia presentada en el Seminario de investigación para la Paz. Convulsión y Violencia en el Mundo. Ed. Departamento de Educación y Cultura. Zaragoza - España 1995

Zuleta, estanislao. Psicoanálisis y Criminología. Editorial Percepción. Bogotá. 1986. 